\title{
Andressa Nuss
}

Filogeografia e padrões de diversificação de três espécies de aves da Mata Atlântica (Myiothlypis leucoblephara, Myrmoderus loricatus e Myrmoderus squamosus)

Phylogeography and patterns of diversification of three Atlantic Forest birds (Myiothlypis leucoblephara, Myrmoderus loricatus and Myrmoderus squamosus) 


\section{Andressa Nuss}

Filogeografia e padrões de diversificação de três espécies de aves da Mata Atlântica (Myiothlypis leucoblephara, Myrmoderus loricatus e Myrmoderus squamosus)

Phylogeography and patterns of diversification of three Atlantic Forest birds (Myiothlypis leucoblephara, Myrmoderus loricatus and Myrmoderus squamosus)

Tese apresentada ao Instituto de Biociências da Universidade de São Paulo, para a obtenção de Título de Doutor em Ciências Biológicas, na Área de Biologia - Genética.

Orientadora: Cristina Yumi Miyaki 
Nuss, Andressa

Filogeografia e padrões de diversificação de três espécies de aves da Mata Atlântica (Myiothlypis leucoblephara, Myrmoderus loricatus e Myrmoderus squamosus)

95 páginas

Tese (Doutorado) - Instituto de Biociências da Universidade de São Paulo.

Departamento de Genética e Biologia Evolutiva.

1. Passeriformes 2.NGS 3.Região Neotropical 4.Demografia histórica

I.Universidade de São Paulo. Instituto de Biociências. Departamento de Genética e Biologia Evolutiva.

Comissão Julgadora:

Prof.(a) Dr.(a)

Prof.(a) Dr.(a)

Prof.(a) Dr.(a)

Prof.(a) Dr.(a) Cristina Yumi Miyaki 
Dedico essa tese a todos os que lutam pela biodiversidade, tarefa tão árdua e complexa nessa pátria mal educada, comandada por covardes gananciosos.

Resistam como cerrado ao fogo, como mangue a maré, como vaga-lume a escuridão. Resistam! 
"Nesses tempos de céus de cinzas e chumbos, nós precisamos de árvores desesperadamente verdes." Mário Quintana 

A minha orientadora Cris, que aceitou o desafio de me supervisionar, por todo o conhecimento compartilhado, a estrutura fabulosa do laboratório e o suporte necessário para realizar um projeto com metodologia científica de ponta.

Nada como ser acolhida com corações quentes ao chegar na maior cidade da América Latina. Aos colegas de laboratório, com quem tive o prazer de conviver: Aline Macedo, Maria Svensson, Ana Bia Bueno, Bruno Lima, Beatriz Raicoski, Fernanda Midori; e em especial a quatro meninas incríveis que ganharam minha total admiração: Rafaella Monteiro, Carla Sardelli, Denise Mendes e Ana Cristina Fazza. Foram 4 anos de amizade, suporte e ótimos momentos de descontração.

Ao Claydson Assis e Gregory Thom que além da amizade e parceria, compartilharam comigo na prática e na teoria seus conhecimentos do extraordinário mundo ornitológico.

Ao Fábio Raposo e Henrique Batalha-Filho que estiveram sempre disponíveis para retirar dúvidas e auxiliar no projeto.

Aos que gentilmente cederam amostras; Adrian Azpiroz, Darío Lijtmaer (MNCN), Richard Prum e Marcos Raposo.

Aos funcionários do Instituto de Biociências, Lucilene, Patrícia, Helenice, Gilmar, Elder e especialmente ao Allan, por todo suporte necessário para a conclusão desse doutorado.

Aos membros da banca examinadora por gentilmente aceitarem participar da defesa de tese.

Agradecimento especial ao Guilherme, por ter me ajudado tanto e de tantas formas, sendo meu fiel companheiro faça chuva ou faça sol, mar adentro ou campo afora, mesmo longe sempre muito perto.

A todos os meus amigos, novos e antigos, fisicamente próximos ou não, expresso o meu profundo agradecimento por me acompanharem nessa jornada. Me sinto muito afortunada ao olhar para traz e ver todas essas múltiplas pegadas ao lado das minhas.

A minha família pelo amor e compreensão, tornando tudo isso possível.

Aos financiadores: CAPES pela implementação da bolsa de doutorado e ao Biota/FAPESP 2013/50297-0 por ter subsidiado esse projeto.

A São Paulo, selva desvairada de pedra e arte. Metrópole catalizadora de transformação, suas engrenagens a frente de outros tempos, proporcionaram meu crescimento pessoal exponencial. Nunca mais serei a mesma, ainda bem!

A Universidade de São Paulo pela estrutura fornecedora de experiências únicas. Movimentei meu corpo e minha alma no interior dessa renomada redoma. Serão lembradas com muito carinho as remadas no por do sol, pedaladas na garoa fina, canções que libertaram minha voz no coral e música erudita de excepcional qualidade gratuita disponível para quem quiser apreciar. 
Sumário

Pág.

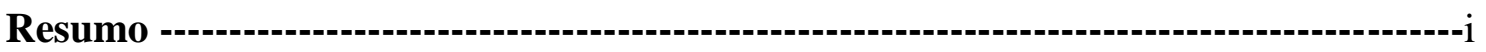

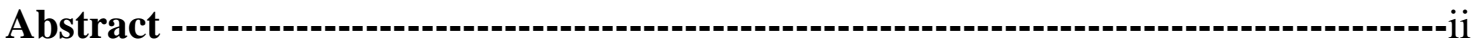

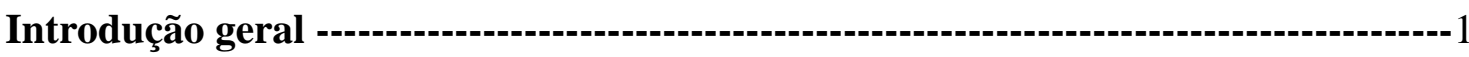

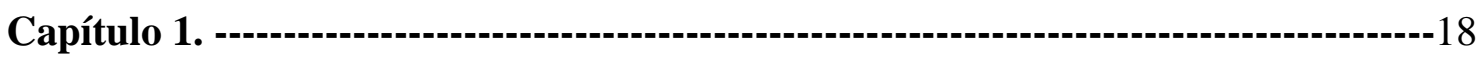

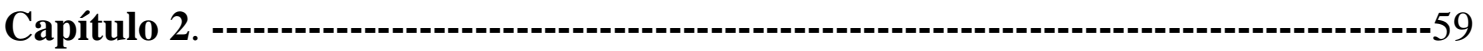

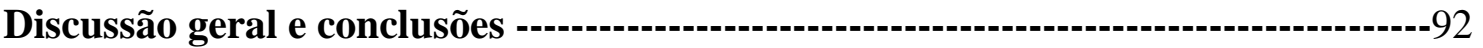


A Floresta Atlântica possui grande heterogeneidade de ambientes e estima-se que hoje está reduzida a $11 \%$ a $16 \%$ de sua área original. Além disso, abriga alto grau de endemismo, sendo considerada como um dos 5 hotspots mundiais de biodiversidade. Para investigar os processos históricos que podem ter sido responsáveis pela distribuição geográfica da diversidade de linhagens genéticas de espécies desse domínio realisamos na presente Tese um estudo filogeográfico de três espécies de passeriformes endêmicos da Floresta Atlântica, Myiothlypis leucoblephara, Myrmoderus loricatus e squamosus. Para acessar a estrutura genética e realizar análises demográficas das espécies foram produzidos dados de milhares de locos, por meio da técnica de Genotyping by Sequencing, de um total de 151 indivíduos de 83 localidades no Brasil, Uruguai e Argentina. A presente Tese inclui dois capítulos. No capítulo 1 a análise de 8.700 SNPs de 86 indivíduos de Myiothlypis leucoblephara indicou a presença de dois grupos genéticos distribuidos em gradientes norte/sul e leste/oeste com claro padrão de isolamento por distância. Ainda, também detectamos expansão populacional no último máximo glacial ( 20 mil anos atrás). No capítulo 2 realizamos um estudo filogeográfico das espécies irmãs Myrmoderus loricatus (35 indivíduos) e M. squamosus (30 indivíduos) utilizando em torno de $\sim 15.500$ SNPs. Diversas análises indicaram padrão de isolamento por distância para ambas espécies e a estimativa de data de separação dessas espécies poderia estar associada à alta atividade tectônica do Vale do Paraíba do Sul. Os dados apresentados na presente Tese permitiram testar algumas hipóteses de diversificação para a Floresta Atlântica e inferir como os processos demográficos atuam moldando a distribuição das linhagens. Além disso, nossos resultados reforçam a importância do uso de grandes quantidades de marcadores para caracterizar populações e inferir como os eventos demográficos aconteceram ao longo da evolução das espécies. 


\begin{abstract}
The Atlantic Forest has a high heterogeneity of types of habitats and today it is reduced to $11 \%$ to $16 \%$ of its original area. In addition, it harbors an elevated degree of endemism and is considered as one of the top five global biodiversity hotspots. In order to investigate the historical processes that may be responsible for the geographic distribution of genetic lineages, we performed a phylogeographic study of three Atlantic Forest endemic passerine species, Myiothlypis leucoblephara, Myrmoderus loricatus and M. squamosus. Data from thousands of loci were produced using Genotyping by Sequencing to access the genetic structure and perform demographic analyzes of a total of 151 individuals from 83 locations in Brazil, Uruguay and Argentina. This Ph.D. Dissertation includes two chapters. In chapter 1 we analyzed $\sim 8,700$ SNPs from 86 individuals of Myiothlypis leucoblephara. The results indicated the presence of two genetic clusters distributed in north/south and east/west gradients with clear isolation by distance pattern. In addition, we also detected population expansion in Last Glacial Maximum ( 20 thousand years ago). In chapter 2 we performed a phylogeographic study of the sister species Myrmoderus loricatus (35 individuals) and M. squamosus (30 individuals) based on $\sim 15,500$ SNPs. Different analyses indicated the presence of isolation by distance for both species and the estimated date of split of these species could be associated with high tectonic activity of Paraíba do Sul Valley. The data presented in this Ph.D. Dissertation allowed us to test some hypotheses of diversification for the Atlantic Forest and to infer how demographic processes act in shaping the distribution of lineages. Moreover, our results reinforce the importance of using large amounts of markers to characterize populations and infer how demographic events happened along the evolution of species.
\end{abstract}




\section{Floresta Atlântica}

A Floresta Atlântica (FA) é uma das maiores florestas úmidas das Américas, originalmente cobrindo cerca de 150 milhões de hectares distribuídos ao longo de uma faixa no leste da América do Sul. A FA foi uma formação florestal praticamente contínua ao longo de grande parte da região litorânea do Brasil, tendo como limite norte o estado do Ceará e o limite sul o estado do Rio Grande do Sul. Limitando sua distribuição a leste encontra-se a costa Atlântica e a oeste, parte do Estado do Mato Grosso do Sul e o leste do Paraguai, além de Misiones na Argentina (GALINDOLEAL; CÂMARA, 2003).

A ação antrópica é responsável há séculos pela devastação de mais de $92 \%$ da mata nativa a partir do início da colonização europeia (DEAN, 1996). Nesse processo de ocupação, a FA experimentou desmatamento e exploração desordenada dos recursos naturais. Como resultado houve grave fragmentação do habitat e hoje existem apenas manchas disjuntas da floresta em locais que desfavorecem a instalação humana, principalmente em topografia mais acidentada que dificulta a mobilidade, impede atividade agrícola e acesso fácil ao escoamento de produção (PINTO et al. 2006). A maior parte da FA remanescente se encontra em pequenos fragmentos, menores que 100 hectares (RANTA et al. 1998) isolados uns dos outros e compostos por floresta de vegetação secundária em estágios médios de sucessão (METZGER, 2000; METZGER et al. 2009). Boa parte dos remanescentes de FA mais expressivos e extensos estão situados no estado de São Paulo, no Parque Estadual da Serra do Mar (LEITÃO FILHO 1994), o qual possui 332 mil hectares que abrangem parte de 24 municípios. Devido à sua vasta extensão e à sua localização, ele constitui um verdadeiro corredor ecológico, interligando os mais significativos remanescentes de FA do país (INSTITUTO FLORESTAL 2006).

Essa degradação do habitat pode, por exemplo, levar à extinção de populações pela perda de habitat ou pela perda de variabilidade genética devido ao isolamento e à perda de habitat. A resposta das espécies à perda de habitat pode variar amplamente e é um assunto complexo que exige estudos, e ainda não é possível mensurar os efeitos genético, ecológico e estrutural ao longo do tempo que a degradação do ambiente vai causar (METZGER et al. 2009). A presença de um mosaico de manchas de habitat (ao invés de uma paisagem contínua) pode refletir fortemente na dinâmica populacional de 
migração, fluxo gênico e deriva genética que podem alterar a distribuição da composição alélica da espécie. Essa composição alélica é importante para que as populações se adaptem às transformações ambientais, assim, em muitos casos a diminuição da variabilidade genética (ex. por perda de alelos) leva ao declínio da população (AVISE 2000, PRIMACK; RODRIGUES, 2001).

Dentro desse contexto de perda de habitat, Myers (1988) cunhou o termo "hotspots" que se refere a áreas prioritárias para a conservação da biodiversidade por possuírem concentração excepcional de espécies com alto grau de endemismo além de terem experimentado degradação e perda de habitat. Para qualificar essas áreas, os dois parâmetros adotados pelo autor foram: conter no mínimo 0,5\% de espécies de plantas globalmente endêmicas e que tenha perdido $70 \%$ ou mais de sua vegetação original. Assim, nesse estudo o autor classifica a costa Atlântica brasileira juntamente com Madagascar e o oeste do Equador como os "hotspots" mais importantes do planeta. A região costeira brasileira, onde a FA ocorre, é fortemente caracterizada pela industrialização em larga escala, com alto grau de urbanização, sendo responsável por gerar em torno de $70 \%$ do PIB nacional (CI-BRASIL et al. 2000). A alta densidade humana define diretamente a grande importância do litoral para o país uma vez que abriga mais da metade da população (FUNDAÇÃO SOS MATA ATLANTICA, 2008; CI-BRASIL et al. 2000). A FA originalmente possuía uma extensão de 1.227,600 km², restando no inicio do século XXI em torno de $11.4 \%$ a $16 \%$ da vegetação original (RIBEIRO et al. 2009; GALINDO LEAL; CÂMARA, 2003). Apesar de ter restado menos de $17 \%$ da cobertura vegetal, os dados são ainda mais preocupantes, pois apenas $35.9 \%$ dos remanescentes florestais estão sob proteção (MYERS et al. 2000) e mesmo nessas áreas a conservação das espécies não está garantida. Conforme Pinto et al. (2006), as unidades de conservação de proteção integral são 684 e abrangem menos de $2 \%$ da extensão do domínio. Infelizmente regiões biogeográficas distintas que ocorrem dentro da FA não estão igualmente representadas nessas áreas protegidas. Assim, esse sistema de unidades de conservação não abrange toda a biodiversidade desse domínio.

A biota da floresta é composta tanto por espécie mais antigas (Pré-Plioceno, entre 5 e milhão de anos atrás) quanto novas (Plioceno, entre 1 milhão 11,5 mil anos atrás; SILVA; CASTELETI, 2003). Analisando a composição da biodiversidade da FA, estima-se que esses complexos ecossistemas contenham $2,7 \%$ das plantas e $2,1 \%$ dos vertebrados endêmicos conhecidos mundialmente. Cerca de 620 espécies de aves habitam a FA sendo 181 endêmicas (STOTZ et al. 1996). Esses números somados aos 
dos mamíferos, anfíbios e répteis resultam em cerca de 1.361 espécies, sendo 567 endêmicas (MYERS et al. 2000). De acordo Brooks et al. (2002), mais de 50\% das plantas e $57 \%$ dos vertebrados globalmente ameaçados de extinção, segundo os critérios da União Mundial para a Natureza (IUCN), encontram-se nos "hostpots". Para os vertebrados terrestres da FA, cerca de 8,5\% das espécies e aproximadamente uma em cada quatro das espécies endêmicas estão ameaçadas de extinção (PAGLIA 2005). Dado esse elevado grau de endemismo e também a forte fragmentação florestal, a FA abriga mais de $60 \%$ espécies presentes na lista oficial da fauna brasileira ameaçada de extinção (TABARELLI et al. 2003; PAGLIA 2005).

Esse alto índice de biodiversidade pode estar associado à heterogeneidade de habitats presentes na FA. Essa característica parece estar associada à grande amplitude de latitude e longitude $\left(1^{\circ}\right.$ a $30^{\circ}$ e $35^{\circ}$ a $60^{\circ}$, respectivamente), estendendo-se por regiões tropicais e subtropicais, bem como variação de altitude (nível do mar até $2.900 \mathrm{~m}$ ) e grande amplitude de temperatura $\left(4^{\circ} \mathrm{C}\right.$ a $\left.32^{\circ} \mathrm{C}\right)$. Essa combinação de fatores proporciona uma grande variedade de macro e micro-habitats ao longo do domínio (GALINDO LEAL; CÂMARA, 2003; SILVA; CASTELETI, 2003). Hoje essa biodiversidade está contida em diversos tipos de formações florestais. As consideradas como latu sensu são: Floresta Ombrófila Densa e Mista (ou Floresta de Araucária); Floresta Estacional Semidecidual e Decidual; e ecossistemas associados, que são os campos sulinos e as áreas com influência flúvio-marinha, compreendidas pelos manguezais e restingas. A FA stricto sensu (ou Floresta Pluvial Atlântica) das regiões sudeste e sul, é composta por três formações florestais distintas: Florestas de Planície Litorânea, Florestas de Encostas e Florestas de Altitude (JOLY et al. 1999; RIZINNI 1997; OLIVEIRA FILHO; FONTES, 2000).

Diversas hipóteses têm sido levantadas visando explicar a origem da diversidade em florestas subtropicais e tropicais. Dentre elas está a hipótese dos museus que associa a maior concentração de endemismo (e maior taxa de diversificação) em áreas de elevadas altitudes (onde condições ambientais seriam mais resilientes às mudanças climáticas) do que em regiões de baixa altitude e com oscilações climáticas maiores (FJELDSA et al. 1997; FJELDSAÅ; LOVETT, 1997). Outra hipótese proposta é a de que os rios podem ter atuado como barreiras para o fluxo gênico podendo resultar em especiação por isolamento (WALLACE 1852). De maneira similar, eventos tectônicos podem ter alterado a paisagem de forma a criar barreiras como, por exemplo, levando a especiação também por isolamento (SILVA; STRAUBE, 1996). A hipótese dos 
gradientes de habitat ou de diversificação parapátrica por seleção postula que a seleção sobre caracteres relacionados à aptidão biológica pode, ao longo do tempo, resultar em isolamento reprodutivo entre grupos de indivíduos de ambientes distintos resultando no surgimento de diferentes espécies adaptadas a diferentes condições ambientais (SMITH et al. 1997). Outra hipótese é a dos refúgios florestais que se baseia em dados paleoclimáticos que indicam que no Pleistoceno o planeta passou por ciclos de avanço e recuo de geleiras continentais devido a mudanças globais de temperatura e umidade (SANT'ANNA NETO; NERY, 2005). Essa hipótese sugere que algumas florestas úmidas podem ter se retraído até tornarem-se remanescentes isolados (também chamados de paleorefúgios), circundados por vegetação aberta durante os períodos de máximo glacial (uma vez que nesses períodos o clima era seco e frio) e expandiam-se durante os períodos mais quentes e úmidos (períodos interglaciais). Como consequência, a distribuição de espécies dependentes de florestas úmidas possivelmente acompanhou os ciclos de expansão e retração das florestas. Se o tempo de isolamento dos organismos nesses remanescentes foi suficiente para promover diferenciação, mesmo com contato posterior devido à expansão florestal, essas linhagens poderiam permanecer sem fluxo gênico (HAFFER 1969; VANZOLINI; WILLIAMS, 1970).

O entendimento dos processos evolutivos que geraram a biodiversidade é importante para a sua conservação. Esse conhecimento permite identificar linhagens que podem ocorrer em áreas sob maior risco de impacto (MORITZ et al. 2000). Dentro desse panorama temos um importante desafio, uma vez que várias espécies de aves da FA estão na lista de espécies com maior risco de extinção dentre as aves neotropicais (STOTZ et al. 1996). Ainda, há a previsão de que diversas espécies desse domínio devem estar extintas em um curto período de tempo (BROOKS; BALMFORD, 1996). Estima-se que devido às mudanças climáticas 600 a 900 espécies de aves sejam extintas até o ano de 2100, a maioria (89\%) em ambientes tropicais (ŞEKERCIOĞLU et al. 2012). Junto com a cobertura da vegetação original, parte do conhecimento que foi perdido é irrecuperável. Assim, diversos padrões e processos da história evolutiva envolvendo as comunidades estarão para sempre extintos sem que pudéssemos sequer ter a chance de compreendê-los.

\section{Filogeografia}

A filogeografia é um campo de estudo relacionado aos princípios e processos que regem as distribuições geográficas das linhagens genealógicas, especialmente 
aquelas dentro e entre espécies estreitamente relacionadas. Como o termo indica, filogeografia inclui a distribuição espacial das linhagens genéticas (AVISE 2000), portanto ela visa reconstruir a filogenia baseada em dados genéticos de forma geograficamente contextualizada, permitindo testar hipóteses sobre a relação causal entre fenômenos geográficos, a distribuição das espécies, e os mecanismos que levam à diversificação (AVISE 2000). Dentro desse contexto, a filogeografia é uma disciplina que disponibiliza informações históricas para o entendimento de padrões de fluxo gênico, colonização, expansão e efeito da distribuição atual da variação genética (por exemplo adaptação local) ao longo de toda a distribuição de uma espécie (AVISE 2000). Uma vez que a filogeografia procura entender as forças microevolutivas que geraram esse padrão de diversidade intra-específica atual, uma das vertentes de investigação mais utilizadas é a identificação, se houver, de barreiras ao fluxo gênico dentro das espécies (AVISE et al. 1987). O surgimento dessa disciplina promoveu importantes avanços em diversas áreas, como por exemplo, biologia da conservação. A análise dos níveis de diversidade genética e a caracterização da distribuição geográfica desta variabilidade dentro de uma espécie são importantes para identificar e priorizar áreas nas quais programas de manejo e conservação devem ser elaborados (MORITZ; FAITH 1998). Dessa forma, as análises de padrões filogeográficos atuam de forma estreitamente direta na verificação de estruturação genética e por consequência na interpretação dos fatores que levaram ao surgimento da diversidade genética observada (MORITZ et al. 2000).

A abordagem filogeográfica foi originalmente desenvolvida utilizando marcadores mitocondriais (AVISE et al. 1987). Ou seja, com o mapeamento da distribuição de grupos de haplótipos de mtDNA de uma espécie ou complexo de espécies para inferir a história das populações (PUORTO et al. 2001). Com esses dados também se estima a variabilidade genética e se caracteriza a estrutura populacional (WILSON 1985). O DNA mitocondrial apresenta algumas características que facilitam sua utilização e o tornam não apenas uma ferramenta apropriada para estudos genéticos, como também uma importante ponte de ligação entre a genética de populações e a filogenia (AVISE et al. 1987). Dentre dessas características estão a herança materna, variabilidade intra-específica relativamente alta sendo sua taxa de evolução maior do que a de segmentos do DNA nuclear de cópia única e presença de múltiplas cópias por célula (AVISE 2000). 
Com os avanços tecnológicos nos processos de sequenciamento e o crescente desenvolvimento de análises bioinformáticas mais complexas, o processamento dos dados moleculares ganhou nova dimensão com a possibilidade de realizar estudos subgenômicos. Segundo Hickerson et al. (2010), a tendência das abordagens filogeográficas é chegar ao estudo genômico de multi-táxons com modelos coalescentes, testando sinal de seleção natural, com modelagem de nicho ecológico e estudos de especiação ecológica. Esta ambiciosa síntese deverá permitir sugerir relações causais entre geografia, alterações climáticas, interações ecológicas e composição genética das populações.

As recentes tecnologias que envolvem o sequenciamento de nova geração (NGS) são ferramentas poderosas para investigar as forças evolutivas que moldam os genomas. Muitas estatísticas sumárias usadas em estudos de demografia, seleção natural, e estrutura populacional são derivadas de estimativas de variação nucleotídica entre múltiplos indivíduos (NIELSEN 2005). O número de sítios segregantes e as frequências alélicas nesses locais estão entre as características mais importantes dos dados de uma perspectiva evolutiva, e são a base de testes de neutralidade comumente utilizados (FU; LI, 1993). Dentro do atual panorama, as demandas são crescentes para que os dados gerados tenham importante papel nas estratégias de conservação, as quais, segundo Moritz (2002), deveriam levar em conta os padrões de distribuição da diversidade genética e também os processos evolutivos envolvidos na origem de tais padrões. Portanto avaliar os dados de forma multidisciplinar, buscando tecnologias mais informativas e abrangentes, leva a um acréscimo fundamental para o nosso conhecimento dos processos históricos biogeográficos, consequentemente a aproximação das respostas para eventos que geraram diversificação.

\section{Sequenciamento de nova geração - NGS}

A atual era genômica conta com várias tecnologias implementadas no mercado (ex. 454/Roche, Illumina, ABI SOLiD, Ion Torrent, PacBio), cada uma das quais possui seu próprio conjunto de características (MARDIS 2017). As primeiras plataformas de NGS surgiram em 2005 e um desses instrumentos foi o 454 FLX (Roche) que usa o método de pirosequenciamento. Esse método depende da detecção de pirofosfato liberado durante a incorporação do nucleotídeo e essa amplificação é realizada em uma solução oleosa emulsificada, denominada PCR em emulsão (BERKA et al. 2010). Outra plataforma foi a HiSeq System (Illumina), a qual realiza o sequenciamento por síntese 
(SBS; MARDIS 2017). As bibliotecas de SBS são amplificadas in situ em um suporte sólido banhado por fluidos com reagentes para a síntese e detecção da reação de sequenciamento. A plataforma de sequenciamento da Illumina se destacou entre as concorrentes, sendo atualmente a mais utilizada (HEAD et al. 2014). A plataforma Ion Torrent (Life Technologies) possui uma abordagem de sequenciamento de DNA diferenciada, visto que a identificação das bases se baseia na alteração de pH quando os nucleotídeos são incorporados na cadeia nova e não pelo uso de ddNTPs ou reações luminosas, como era o caso das tecnologias utilizadas até então (MARDIS 2017). O método empregado para o sequenciamento na plataforma SOLiD (Applied Biosystems) faz uso de fragmentos de DNA ligados a esferas (beads), quando a base é incorporada na cadeia sendo sintetizada há emissão de um sinal luminoso do fluoróforo acoplado à base correspondente e esse sinal é capturado pelo sistema óptico do sequenciador (MARDIS 2017).

Essas tecnologias tem em comum a capacidade de gerar rapidamente enormes quantidades de dados de sequências de forma relativamente econômica. Assim, um grande número de marcadores genéticos é analisado, o que por sua vez, auxilia na busca da base genética de variações fenotípicas ecológicas importantes. Muitas questões relevantes podem ser respondidas com dados de sequências em grande quantidade (GLENN 2011). Por exemplo, a comparação do nível de variabilidade genética em regiões associadas a genes e em regiões intergênicas pode permitir inferir sobre a ação da seleção natural nas populações. Em se tratando de estudos de ecologia molecular, houve avanços importantes. Enquanto habitualmente estudos baseados em espéciesmodelo eram predominantes, com esses avanços os pesquisadores puderam estudar populações naturais de organismos e abordar questões ecológicas e evolutivas em uma escala de precisão impensável anteriormente, especialmente pelo crescente número de espécies com genomas sequenciados, viabilizando cada vez mais utilizar essa abordagem em espécies não-modelo. Nesse contexto, um grande número de espécies com relevância ecológica e conservacionista pode se beneficiar da era genômica (KOHN et al. 2006; EKBLOM; GALINDO, 2011).

Uma metodologia de redução da porção do genoma a ser sequenciada muito utilizada atualmente é o genotyping-by-sequencing (GBS; ELSHIRE et al. 2011). Esse método é muito similar ao Restriction-site associated DNA sequencing (RAD-seq; DAVEY, BLAXTER, 2010). Ambas envolvem uma etapa inicial de redução de complexidade do genoma alvo (descrita a seguir), mas para a preparação da biblioteca 
de GBS os fragmentos gerados não são selecionados pelo tamanho e seu custo é comparativamente menor (ELSHIRE et al. 2011). Assim, o DNA total é digerido com uma ou mais enzimas de restrição gerando vários fragmentos que são ligados a adaptadores em ambas as extremidades. Esses adaptadores servem, então, como iniciadores em uma reação de PCR para aumentar a quantidade desses segmentos (BAIRD et al. 2008). Em seguida essa biblioteca é sequenciada por NGS. Com isso milhares de marcadores em todo o genoma são sequenciados (DAVEY; BLAXTER, 2010). A introdução recente de instrumentos capazes de produzir milhões de leituras de sequência de DNA em uma única corrida está mudando rapidamente a paisagem da genética, fornecendo a capacidade de responder perguntas complexas e interdisciplinares com inimaginável rapidez (MARDIS 2017).

\section{As espécies-modelo}

\section{Myiothlypis leucoblephara}

A espécie Myiothlypis leucoblephara (Vieillot 1817), também conhecida como pula-pula-assobiador, pertence à família Parulidae Wetmore, Friedmann, Lincoln, Miller, Peters, van Rossem, Van Tyne \& Zimmer 1947, é endêmico da FA. Ocorre no Paraguai, Argentina, Uruguai e no sul e sudeste do Brasil. Habita preferencialmente o interior de matas úmidas e sombreadas em regiões de serra, locomovendo-se por meio de pulos no solo ou pouco acima dele, na parte baixa da vegetação (SICK 1997). Seu tarso avantajado lhe permite utilizar a técnica de forrageio "glean", que se baseia predominante na escolha de alimento no solo ou próximo dele, sem uso de movimento acrobático (FITZPATRICK, 1985; REMSEN JR; ROBINSON, 1990). Sua dieta é basicamente insetívora, com predominância de coleópteros e himenópteros, e também aracnídeos (CHATELLENAZ 2008). Possui cauda longa e larga, suas asas são verdeescuro e possui o píleo acinzentado, apresenta círculo em torno do olho e sobrancelha estreita brancos, mede $14,5 \mathrm{~cm}$ e possui coberteiras inferiores da cauda amareladas (SICK 1997).

A família Parulidae apresenta em torno de 22 espécies e dentre estas, pelo menos 7 espécies que ocorrem na FA (LIMA 2013). Estudos filogenéticos moleculares recentes têm revelado que muitas dessas famílias tradicionais dentro dos passeriformes, não são agrupamentos monofiléticos, levando a uma série de revisões para as atuais classificações (KLICKA et al. 2007). Lovette et al. (2010), em um estudo com 110 táxons, sugerem diversas modificações dentro da família, subdividindo-a em 14 
gêneros. Segundo os resultados das análises filogenéticas moleculares, a polifilia deste gênero ficou evidente, sendo sugerida a utilização do gênero Myiothlypis Cabanis, 1850 para 16 táxons que pertenciam anteriormente ao gênero Basileuterus. Entre as espécies que sofreram essa revisão está Myiothlypis leucoblephara, alteração incluída na lista de espécies de aves do Brasil de 01/01/2014 pelo Comitê Brasileiro de Registros Ornitológicos(CBRO, 2015)

Batalha Filho et al. (2012), em um estudo com Myiothlypis leucoblephara baseado em marcadores nucleares e mitocondriais, abordaram algumas questões, dentre elas, se a estruturação genética atual da espécie concordava com os padrões observados para outros organismos da FA e como o último máximo glacial afetou o tamanho populacional efetivo dessa espécie. A abordagem utilizada baseada em modelos demográficos permitiu inferir a história evolutiva de $M$. leucoblephara e a dinâmica de diversificação dentro da FA. No entanto, o trabalho revelou o primeiro exemplo de um organismo desse domínio sem uma forte estruturação genética populacional e cujo tamanho da população não se alterou durante o último máximo glacial. A controvérsia dos resultados pode estar relacionada à falta de marcadores, e como principal consequência disso, ocorreria a limitação e o enfraquecimento das inferências realizadas, evidenciando um possível viés na análise.

\section{Myrmoderus loricatus e Myrmoderus squamosus}

As espécies Myrmoderus loricatus (Lichtenstein, 1823) e Myrmoderus squamosus (Pelzeln, 1868) (comumente chamados de formigueiro-assobiador e papaformiga-de-grota, respectivamente) pertencem à Família Thamnophilidae Swainson, 1824. Essa família faz parte da ordem Passeriformes e possui um elevado número de espécies no Brasil, em torno de 238 (CBRO, 2015). Seus representantes são majoritariamente insetívoros e estão praticamente restritos a florestas de altitude mais baixas da região neotropical, habitando dos Andes até o sul do Brasil (ZIMMER; ISLER, 2003). O gênero Myrmeciza, considerado um dos mais diversos dentro da família, foi alvo de uma revisão taxonômica por apresentar uma série de incertezas e controversa classificação das espécies (ISLER et al. 2013). Devido a classificações genéricas e divergências entre autores, a composição do gênero vinha sendo modificada ao longo do tempo (Zimmer 1932; Peters 1951) e a polifilia do gênero foi confirmada por estudos moleculares (eg. IRESTEDT et al. 2004; BRUMFIELD et al. 2007). Assim, Isler et al. (2013), baseados em características morfológicas, comportamentais, 
ecológicas e filogenéticas, sugeriram a realocação de $M$. loricatus e $M$. squamosus do gênero Myrmeciza para o atualmente reconhecido gênero Myrmoderus, o que foi aceito na lista de aves do Brasil de 01/01/2014 do Comitê Brasileiro de Registros Ornitológicos (CBRO, 2015).

As duas espécies alvo do presente projeto são consideradas irmãs e, juntamente com $M$. ferruginea e $M$. ruficauda, formam um clado monofilético bem suportado. No entanto, diferentemente de Sibley e Monroe (1990), Sick (1997) descreve M. squamosus como subespécie de $M$. loricatus, considerando aspectos como plumagem muito semelhante, bem como seus hábitos e sons. Possuem distribuição parapátrica, com áreas sobrepostas na região central da FA, da qual são endêmicas, habitando tanto áreas de várzea até florestas úmidas, do nível do mar até $1000 \mathrm{~m}$ ou superior (RIDGELY; TUDOR, 2009).

Raposo do Amaral et al. (2013), em um estudo de filogeografia multilocos, detectaram pouco ou nenhum fluxo gênico entre as espécies em questão, justificado pelo desenvolvimento de barreiras reprodutivas ou exclusão competitiva. Além disso, os resultados apresentados pelos autores ressaltaram a importância de utilizar diversos marcadores independentes visando obter resultados mais robustos. O efeito de amostragem inadequada pode, dentre outras consequências, comprometer as estimativas de tempo de divergência e a reconstrução da história demográfica das espécies, uma vez que a história de um ou poucos genes por vezes não representa a divergência dentro da espécie (EDWARDS; BEERLI, 2000).

\section{Capítulos da tese}

A presente Tese apresenta dois capítulos que descrevem estudos filogeográficos usando dados de milhares de SNPs de Myiothlypis leucoblephara (Capítulo1) e dos táxons irmãos Myrmoderus squamosus e Myrmoderus loricatus (Capítulo 2). Ambos estudos visaram contribuir com aporte teórico no entendimento da Biogeografia da Floresta Atlântica e na história evolutiva das espécies em questão. Pretendemos submeter os manuscritos às revistas: Molecular Phylogenetics and Evolution e Molecular Ecology, respectivamente. 
AVISE, J.C. Phylogeography: The History and Formation of Species. Harvard University Press, Cambridge, 2000.

AVISE, J.C.; ARNOLD, J.; BALL, R. M.; BERMINGHAM, E.; LAMB, T.; NEIGEL, J. E.; REEB, C. A. et al. Intraspecific phylogeography: The mitochondrial DNA bridge between population genetics and systematics. Annual Review of Ecology and Systematic, v.18, p. 489-522, 1987.

BAIRD, N. A; ETTER, P. D.; ATWOOD, T. S.; CURREY, M. C.; SHIVER, A. L.; LEWIS, Z. A.; SELKER, E. U. et al. Rapid SNP discovery and genetic mapping using sequenced RAD markers. PloS One, v. 3, p. 3376, 2008.

BATALHA-FILHO, H.; CABANNE, G.S.; MIYAKI, C.Y. Phylogeography of an Atlantic forest passerine reveals demographic stability through the last glacial maximum. Molecular Phylogenetics and Evolution, v. 65, p. 892-902, 2012.

BERKA, J.; CHEN, Y.J.; LEAMON, J.H., LEFKOWITZ, S.; LOHMAN, K.L.; MAKHIJANI, V.B.; WEINER, M.P. Bead emulsion nucleic acid amplification. U.S. Patent No. 7,842,457. U.S. Patent and Trademark Office, 2010.

BROOKS, T. M.; BALMFORD, A. Atlantic forest extinctions. Nature, v. 380, n. 6570, p. 115-115, 1996.

BROOKS, T. M.; MITTERMEIER, R. A.; MITTERMEIER, C. G.; DA FONSECA, G. A.; RYLANDS, A. B.; KONSTANT, W. R.; FLICK, P. et al. Habitat loss and extinction in the hotspots of biodiversity. Conservation Biology, v. 16, n. 4, p. 909-923, 2002.

BRUMFIELD, R.T.; TELlO, J.G.; CHEVIRON, Z.A.; CARLING, M.D.; CROCHET, N.; ROSENBERG, K.V. Phylogenetic conservatism and antiquity of a tropical specialization: Army-ant-following in the typical antbirds (Thamnophilidae). Molecular Phylogenetics and Evolution, v. 45, p. 1-13, 2007.

CBRO - Comitê Brasileiro de Registros Ornitológicos. Listas das aves do Brasil, 2015. Disponível em http//www.cbro.org.br (acessado em 01/05/2019). 
CHATEllENAZ, Mario L. Ecología alimentaria de dos especies simpátricas del género Basileuterus en el Noreste de Argentina. El Hornero, v. 23, n. 2, p. 87-93, 2008.

CI-BRASIL (Conservation International do Brasil), Fundação SOS Mata Atlântica, Fundação Biodiversitas, IPÊ, SMA-SP \& SEMAD-MG. Avaliação e Ações Prioritárias para Conservação da Biodiversidade da Mata Atlântica e Campos Sulinos. MMA/SBF, Brasília, 2000.

DAVEY, J. W.; BLAXTER, M. L. RADSeq: next-generation population genetics. Briefings in Functional Genomics, v. 9, p. 416-423, 2010.

EDWARDS, S. V.; BEERLI, P. Perspective: gene divergence, population divergence, and the variance in coalescence time in phylogeographic studies. Evolution, v. 54, p. 1839-1854, 2000.

EKBLOM, R.; GALINDO, J. Applications of next generation sequencing in molecular ecology of non-model organisms. Heredity, v. 107, p. 1-15, 2011.

ELSHIRE, R.J.; GLAUBITZ, J.C.; SUN, Q.; POLAND, J. A.; KAWAMOTO, K.; BUCKLER, E. S.; MITCHELL, S. E. A robust, simple genotyping-by-sequencing (GBS) approach for high diversity species. PloS One, v. 6, p. e19379, 2011.

FITZPATRICK, John W. Form, foraging behavior, and adaptive radiation in the Tyrannidae. Ornithological Monographs, p. 447-470, 1985.

FJELDSA A, J.; EHRLICH, D.; LAMBIN, E.; PRINS, E. Are biodiversity 'hotspots' correlated with current ecoclimatic stability? A pilot study using the NOAAAVHRR remote sensing data. Biodiversity \& Conservation, v. 6, n. 3, p. 401-422, 1997.

FJELDSAÅ, J.; LOVETT, J.C. Geographical patterns of old and young species in African forest biota: the significance of specific montane areas as evolutionary centres. Biodiversity \& Conservation, v. 6, n. 3, p. 325-346, 1997.

FU, Y.X.; LI, W.H. Statistical tests of neutrality of mutations. Genetics, v. 133, p. 693-709, 1993.

FUNDAÇÃO SOS MATA ATLÂNTICA/INSTITUTO NACIONAL DE PESQUISAS ESPACIAIS. Atlas dos Remanescentes Florestais da Mata Atlântica, 
Período de 2000 a 2005, 2008. Disponível em www.sosma.org.br (acessado em 10 05/2018).

GAlindo-LEAL, C.G.; CÂMARA, I.G. The Atlantic Forest of South America: biodiversity status, threats, and outlook. Island Press, 2003.

GLENN, T. C. Field guide to next-generation DNA sequences. Molecular Ecology Resources, v. 11, p. 759-769, 2011.

HAFFER, J. Speciation in Amazonian forest birds. Science, v. 165, n. 3889, p. 131$137,1969$.

HEAD, S.R.; KOMORI, H. K.; LAMERE, S. A.; WHISENANT, T.; VAN NIEUWERBURGH, F.; SALOMON, D. R.; ORDOUKHANIAN, P. Library construction for next-generation sequencing: overviews and challenges. Biotechniques, v. 56, p. 61-77, 2014.

HICKERSON, M. J.; CARSTENS, B. C.; CAVENDER-BARES, J.; CRANDALL, K. A.; GRAHAM, C. H.; JOHNSON, J. B.; RISSLER, L. et al. Phylogeography's past, present, and future: 10 years after. Molecular Phylogenetics and Evolution, v. 54, p. 291-301, 2010.

INSTITUTO FlORESTAL. 2006. Parque Estadual da Serrado Mar: Plano de Manejo. Instituto Florestal - Secretaria do Meio Ambiente do Estado de São Paulo. http://www.iflorestal.sp.gov.br (acesso em 25/10/2008).

IRESTEDT, M.; FJELDSÅ, J.; NYLANDER, J. A. A.; ERICSON, P. G. P. Phylogenetic relationships of typical antbirds (Thamnophilidae) and test of incongruence based on Bayes factors. BMC Evolutionary Biology, v. 4, p. 23, 2004.

ISLER, M. L.; BRAVO, G. A.; BRUMFIELD, R. T. Taxonomic revision of Myrmeciza (Aves: Passeriformes: Thamnophilidae) into 12 genera based on phylogenetic, morphological, behavioral, and ecological data. Zootaxa, v. 3717, n. 4, p. 469-497, 2013.

JOLY, C.A.; AIDAR, M.P.M.; KLINK, C.A. Evolution of the Brazilian phytogeography classification systems: implications for biodiversity conservation. Ciência e Cultura, v. 51, n. 5/6, p. 331-348, 1999. 
KLICKA, J.; BURNS, K.; SPELLMAN, G. M. Defining a monophyletic Cardinalini: a molecular perspective. Molecular Phylogenetics and Evolution, v. 45, p. 1014-1032, 2007.

KOHN, M. H.; MURPHY, W. J.; OSTRANDER, E. A.; WAYNE, R. K. Genomics and conservation genetics. Trends in Ecology \& Evolution, v. 21, p. 629-637, 2006.

LEITÃO FILHO, H.F. Diversity of arboreal species in Atlantic rain forest. Anais da Academia Brasileira de Ciências, v. 66, p. 91-96, 1994.

LIMA, L. M. Aves da Mata Atlântica: riqueza, composição, status, endemismos e conservação. Tese de Doutoramento. Universidade de São Paulo. 2013

LOVETTE, I. J.; PÉREZ-EMÁN, J. L.; SUllivAN, J. P.; BANKS, R. C.; FIORENTINO, I.; CÓRDOBA-CÓRDOBA,S.; ECHEVERRY-GALVIS, M. et.al. A comprehensive multilocus phylogeny for the wood-warblers and a revised classification of the Parulidae (Aves). Molecular Phylogenetics and Evolution, v. 57, n. 2, p. 753$770,2010$.

MARDIS, E. R. DNA sequencing technologies: 2006-2016. Nature Protocols, v. 12, p. 213-218, 2017.

METZGER, J.P. Tree functional group richness and landscape structure in a Brazilian tropical fragmented landscape. Ecological Applications, v. 10, n. 4, p. $1147-$ $1161,2000$.

METZGER, J.P.; MARTENSEN, A.C.; DIXO, M.; BERNACCI, L.C.; RIBEIRO, M.C.; TEIXEIRA, A.M.G.; PARDINI, R. Time-lag in biological responses to landscape changes in a highly dynamic Atlantic forest region. Biological Conservation, v. 142, n. 6, p. 1166-1177, 2009.

MORITZ, C.; FAITH, D.P. Comparative phylogeography and the identification of genetically divergent areas for conservation. Molecular Ecology, v. 7, p. 419-429, 1998.

MORITZ, C.; PATTON, J.; SCHNEIDER, C.; SMITH, T. Diversification of rainforest faunas: an integrated molecular approach. Annual Review of Ecology and Systematics, v.31, p. 533-563, 2000. 
MORITZ, C. Strategies to protect biological diversity and the evolutionary processes that sustain it. Systematic Biology, v.51, p. 238-254, 2002.

MYERS, N. Threatened biotas:" hot spots" in tropical forests. Environmentalist, v. 8, n. 3, p. 187-208, 1988.

MYERS, N.; MITTERMEIER, R.A.; MITTERMEIER, C.G.; FONSECA, G.A.B.D.; KENT, J. Biodiversity hotspots for conservation priorities. Nature, v. 403, p. $853-858,2000$.

NIELSEN, R. Molecular signatures of natural selection. Annual Review of Genetics, v. 39, p. 197-218, 2005.

OLIVEIRA FILHO, A.T.; FONTES, M.A.L. Patterns of floristic differentiation among Atlantic Forests in southeastern Brazil and the influence of Climate. Biotropica, v. 32, n. 4b, p. 793-810, 2000.

PAGLIA, A.P. Panorama geral da fauna ameaçada de extinção no Brasil. In A. B. M. MACHADO, C. SOARES MARTINS \& G.M. DRUMOND (eds.). Lista da Fauna Brasileira Ameaçada de Extinção - Incluindo a Lista das Quase Ameaçadas e Deficientes em Dados. p. 17-22. Fundação Biodiversitas, Belo Horizonte, 2005.

PINTO, L.P.; BEDÊ, L.; PAESE, A.; FONSECA, M.; PAGLIA, A.; LAMAS, I. et al. Mata Atlântica Brasileira: os desafios para conservação da biodiversidade de um hotspot mundial. Biologia da Conservação: Essências. RiMa, São Carlos, p. 69-96, 2006.

PRIMACK, R.B.; RODRIGUES, E. Biologia da Conservação. E. Rodrigues, 2001 .

PUORTO, G.; DA GRAÇA SALOMÃO, M.; THEAKSTON, R. D.G.; THORPE, R. S.; WARRELL, D. A.; WÜSTER, W. Combining mitochondrial DNA sequences and morphological data to infer species boundaries: phylogeography of lanceheaded pitvipers in the Brazilian Atlantic forest, and the status of Bothrops pradoi (Squamata: Serpentes: Viperidae). Journal of Evolutionary Biology, v. 14, p. 527-538, 2001. 
RANTA, P.; BLOM, T.O.M.; NIEMELA, J.; JOENSUU, E.; SIITONEN, M. The fragmented Atlantic rain forest of Brazil: size, shape and distribution of forest fragments. Biodiversity \& Conservation, v. 7, n. 3, p. 385-403, 1998.

RAPOSO DO AMARAL, F.; ALBERS, P. K.; EDWARDS, S. V.; MIYAKI, C. Y. Multilocus tests of Pleistocene refugia and ancient divergence in a pair of Atlantic Forest antbirds (Myrmeciza). Molecular Ecology, v. 22, n. 15, p. 3996-4013, 2013.

REMSEN JR, J. V.; ROBINSON, Scott K. A classification scheme for foraging behavior of birds in terrestrial habitats. Studies in Avian Biology, v. 13, p. 144-160, 1990.

RIBEIRO, C.A.; METZGER, J.P.; MARTENSEN, A.C.; PONZONI, F.J.; HIROTA, M.M. The Brazilian Atlantic Forest: How much is left, and how is the remaining forest distributed? Implications for conservation. Biological Conservation. v. 142, p. 1141-1153, 2009.

RIDGELY, R. S.; TUDOR, G. Field Guide to the Songbirds of South America. University of Texas Press, 2009. 736 p.

RIZZINI, C.T.; Tratado de Fitogeografia do Brasil. 2 ed. Âmbito Cultural Edições Ltda, 1997.

SANT'ANNA-NETO, J.L.; NERY, J.T. Variabilidade e mudanças climáticas no Brasil e seus impactos. In: Souza GRG, Suguio K, Oliveira MAS, Oliveira PL (Eds). Quaternário do Brasil. Holos Editora, p. 28-50, 2005.

ŞEKERCIOĞLU, C.H.; PRIMACK, R.B.; WORMWORTH, J. The effects of climate change on tropical birds. Biological Conservation, v. 148, p. 1-18, 2012.

SIBLEY, C. G.; MONROE, B. L. Distribution and Taxonomy of Birds of the World. Yale University Press, 976 p, 1990.

SICK, H. Ornitologia Brasileira. Nova Fronteira, 862 p, 1997.

SILVA, J.M.C.; CASTELETI, C.H.M. Status of the biodiversity of the Atlantic Forest of Brazil. In: C. Galindo-Leal \& I.G. Câmara (eds.). The Atlantic Forest of 
South America: Biodiversity Status, Threats, and Outlook. Center for Applied Biodiversity Science and Island Press, p. 43-59, 2003.

SILVA, J.M.C.; STRAUBE, F.C. Systematics and biogeography of scaled woodcreepers (Aves: Dendrocolaptidae). Studies on Neotropical Fauna and Environment, v. 31, p. 3-10, 1996.

SMITH, T.B.; WAYNE, R.K.; GIRMAN, D.J.; BRUFORD, M.W. A role for ecotones in generating rainforest biodiversity. Science, v. 276, n. 5320, p. 1855-1857, 1997.

STOTZ, D.F.; FITZPATRICK, J.W.; PARKER III, T.A.; MOSKOVITS, D.K.; SNOW, D. Neotropical Birds: Ecology and Conservation, University of Chicago Press, 478 p, 1996.

TABARELLI, M.; VICENTE, A.; BARBOSA, D.C.A. Variation of seed dispersal spectrum of woody plants across a rainfall gradient in north-eastern Brazil. Journal of Arid Environments, v. 53, n. 2, p. 197-210, 2003.

VANZOLINI, P.E.; WILLIAMS, E. E. South American anoles: the geographic differentiation and evolution of the Anolis chrysolepis species group (Sauria, Iguanidae). Arquivos de Zoologia, v. 19, n. 1-2, p. 1-298, 1970.

WALLACE, A.R. On the monkeys of the Amazon. Proceedings of the Zoological Society of London, v. 20, p. 107-110, 1852.

ZIMMER, K.; ISLER, M.L. White-bibbed antbird (Myrmeciza loricata). In: del Hoyo, J., Elliott, A., Sargatal, J., Christie, D.A. \& de Juana, E. (eds.). Handbook of the Birds of the World Alive. Lynx Edicions, Barcelona, 2003. Disponível em http://www.hbw.com/node/56825 (acessado em 03/11/2018). 
Na presente tese descrevemos padrões de diversificação de três espécies de aves endêmicas da Floresta Atlântica (FA), Myiothlypis leucoblephara, Myrmoderus loricatus e Myrmoderus squamosus, e inferimos potenciais processos históricos que moldaram a diversidade genética desses organismos. Para aumentar nossa compreensão da dinâmica histórica da FA e contribuir com o entendimento da biodiversidade da região Neotropical, foi essencial a testar modelos de diversificação e hipóteses relacionadas a esses modelos. As análises indicaram que a hipótese dos refúgios florestais parece ter sido importante na diversificação das espécies estudadas e isto corrobora outros estudos com organismos da FA (e.g. CABANNE et al. 2007, MARTINS et al. 2008, THOMÉ et al. 2010). Como exemplo da influência das variações climáticas detectada nas espécies de estudo, podemos citar: 1) sinal de expansão demográfica em $M$. leucoblephara no período correspondente ao último máximo glacial, resultado associado à instabilidade no sul da FA; 2) variação da diversidade genética ao longo da FA em Myrmoderus spp. com a maior diversidade genética associada a áreas mais estáveis, ao norte da FA em M. loricatus. Além da hipótese dos refúgios, pudemos inferir que as atividades tectônicas ocorridas no Quaternário, como a formação do Vale do Paraíba do Sul, possivelmente atuaram na diversificação das espécies irmãs do gênero Myrmoderus. Nesse contexto, o presente estudo revela um cenário complexo no qual os padrões de biodiversidade na FA resultaram de interações entre eventos geológicos antigos que moldaram a distribuição de linhagens e eventos climáticos mais recentes, que impulsionaram processos evolutivos. Além desses eventos que possivelmente atuaram na diversidade genética desses táxons, salientamos que atributos ecológicos intrínsecos, como dependência florestal, territorialismo e flexibilidade de habitat, conferem características únicas às espécies. Compreender a interação desses fatores ao longo do tempo e suas consequências na diversificação dos organismos é um grande desafio. Sugerimos que novas investigações multidisciplinares, como a associação entre dados genômicos e ambientais, incluindo modelagem de nicho ecológico, podem proporcionar uma melhor compreensão de como a distribuição da diversidade genética observada se moldou.

Observamos para as três espécies, fluxo gênico em curtas distâncias suficiente para impedir a diferenciação genética local. Esse resultado não havia sido detectado em estudos prévios baseados em poucos marcadores. Assim, possivelmente a detecção de isolamento por distância parece ser consequência do aumento substancial no número de marcadores. Isso reforça a importância da análise de grandes quantidades de dados 
cujos resultados permitem identificar melhor mecanismos de dispersão e padrões de conectividade entre indivíduos, além de serem excelentes ferramentas para inferir como a heterogeneidade ecológica e ambiental molda a distribuição da variação genética na natureza (WANG; BRADBURD 2014).

Estudos filogeográficos têm amostrado progressivo uso de maior quantidade de locos, em parte motivado por trabalhos teóricos que mostraram que as estimativas dos principais parâmetros demográficos melhoram à medida que o número de locos aumenta (GARRICK et al. 2015). Isso aumenta a resolução e a precisão das investigações demográficas históricas e essa estratégia está apenas começando a ser aplicada aos organismos da FA. Assim, nosso trabalho é um dos primeiros estudos aplicando metodologia de sequenciamento de nova geração utilizando aves desse domínio como modelo, e podemos concluir que está de acordo com outros estudos que mostram que reanálises da história demográfica de organismos usando mais marcadores genéticos resultam em resultados mais robustos (MCCORMACK et al. 2012). 
CABANNE, G. S.; SANTOS, F. R.; MIYAKI, C. Y. Phylogeography of Xiphorhynchus fuscus (Passeriformes, Dendrocolaptidae): vicariance and recent demographic expansion in southern Atlantic forest. Biological Journal of the Linnean Society. v. 91, p. 73-84, 2007.

GARRICK, R. C.; BONATELLI, I. A.; HYSENI, C.; MORALES, A.; PELLETIER, T. A.; PEREZ, M. F.; CARSTENS, B. C. The evolution of phylogeographic data sets. Molecular Ecology, v. 24. n. 6, p. 1164-1171, 2015.

MARTINS, F. M.; TEMPLETON, A. R.; PAVAN, A. C. O.; KOHLBACH, B. C.; MORGANTE, J. S. Phylogeography of the common vampire bat (Desmodus rotundus): marked population structure, Neotropical Pleistocene vicariance and incongruence between nuclear and mtDNA markers. BMC Evolutionary Biology, v. 9, p. 294XXX?, 2009.

MCCORMACK, J. E.; MALEY, J. M.; HIRD, S. M.; DERRYBERRY, E. P.; GRAVES, G. R.; BRUMFIELD, R. T. Next-generation sequencing reveals phylogeographic structure and a species tree for recent bird divergences. Molecular Phylogenetics and Evolution, v. 62, p. 397-406, 2012.

THOMÉ, M. T. C.; ZAMUDIO, K. R.; GIOVANELLI, J. G. R.; HADDAD, C. F. B.; BALDISSERA F. A. JR.; ALEXANDRINO, J. M. B. Phylogeography of endemic toads and post-Pliocene persistence of the Brazilian Atlantic forest. Molecular Phylogenetics and Evolution, v. 55, p. 1018-1031, 2010.

WANG, I. J.; BRADBURD, G. S. Isolation by environment. Molecular Ecology, v. 23 , p. 5649-5662, 2014. 